TI 2016-045/VII

Tinbergen Institute Discussion Paper

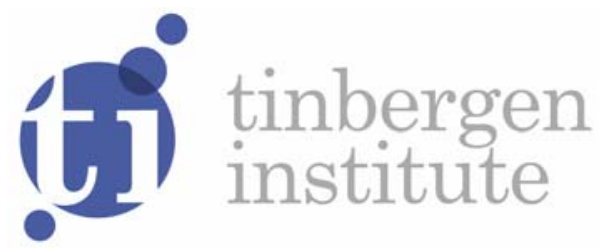

The Magic of the Personal Touch:

Field Experimental Evidence on Money and Appreciation as Gifts

Christiane Bradler

Susanne Neckermann²

1 ZEW Centre for European Economic Research Mannheim;

2 Erasmus School of Economics, Erasmus University Rotterdam, Tinbergen Institute, the Netherlands. 
Tinbergen Institute is the graduate school and research institute in economics of Erasmus University Rotterdam, the University of Amsterdam and VU University Amsterdam.

More TI discussion papers can be downloaded at http://www.tinbergen.nl

Tinbergen Institute has two locations:

Tinbergen Institute Amsterdam

Gustav Mahlerplein 117

1082 MS Amsterdam

The Netherlands

Tel.: +31(0)20525 1600

Tinbergen Institute Rotterdam

Burg. Oudlaan 50

3062 PA Rotterdam

The Netherlands

Tel.: +31(0)10 4088900

Fax: +31(0)10 4089031 


\title{
The Magic of the Personal Touch: Field Experimental Evidence on Money and Appreciation as Gifts*
}

\author{
Christiane Bradler ${ }^{\dagger}$ and Susanne Neckermann $n^{\ddagger}$
}

May 2016

\begin{abstract}
This paper makes use of two field experiments to explore individual effort responses to gifts. We extend the literature by looking at nonfinancial gifts and gifts that combine financial and nonfinancial elements with or without adding a "personal touch." We find that non-pecuniary gifts that signal worker appreciation induce reciprocity. Most importantly, we find that there are interaction effects between money and appreciation. While money and appreciation are individually effective, they only work well together when they are combined with a personal touch. This points to the importance of interpersonal elements in gift giving and has important implications for how to effectively elicit worker effort.
\end{abstract}

JEL Classification: C93, M52

Keywords: gift exchange, reciprocity, employee performance, pro-social behavior, gratitude, personal touch, field experiment

${ }^{*}$ We gratefully acknowledge comments and suggestions by numerous seminar and conference participants. Special thanks goes to Michael Kosfeld, Steve Levitt, John List, and Nick Zubanov. We thank Ann-Kathrin Koessler, Mattie Toma, and Jeannine van Reeken for excellent research assistance. The experiment has been conducted within the ethical guidelines of our home institutions.

${ }^{\dagger}$ ZEW Centre for European Economic Research Mannheim

${ }^{\ddagger}$ Erasmus University Rotterdam, Tinbergen Institute, ZEW, and CREMA 


\section{Introduction}

Gift giving is a widespread phenomenon, not only in social settings, but also in the professional realm. Many firms, for instance, use gifts as a means of reinforcing their relationships with their clients and employees. While gifts can serve many purposes, one objective of gift giving, especially common in corporate settings, is the elicitation of reciprocity. ${ }^{1}$

Gifts utilized by businesses can take many different forms. Some gifts are purely financial, such as a year-end bonus, a rebate, or above market-clearing wages. Other gifts, for example a thank you card or a pat on the back, have no financial component. In many cases, gifts have both a financial and a non-financial component, for instance an expression of worker appreciation accompanied by a financial gift.

When gifts include both financial and non-financial elements, these two components can be combined in more or less thoughtful ways, where thoughtfulness can, for example, be conveyed by adding a personal touch. Consider a supervisor seeking to express her appreciation for her workers by giving them a financial gift. One approach would be to send a mass e-mail to all employees expressing her appreciation and noting that a wage gift will be included in the upcoming paycheck. Or, she could write a series of personalized emails that convey this message. Alternatively, she could take the time to stop by each employee's desk, put a hand on the employee's shoulder, and deliver a heartfelt speech of appreciation while handing the employee a check in an envelope with a hand-written message.

The existing literature, outlined below, has mainly focused on financial gifts, and little is known about the effectiveness of nonfinancial gifts, combined gifts, and the impact of a personal touch. In this paper we use two field experiments in professional settings to explore these open issues and to look into the extent to which financial and nonfinancial gifts and their combinations with and without personal touch elicit reciprocity from the recipients. We use cash as a financial reward and convey gratitude and appreciation (the nonfinancial gift) via a thank you card. We combine the financial and the non-financial gift in two different ways: one that requires a significant investment of time and effort (the gift has a handmade element) and one that requires little investment of time and effort (the gift does not have a handmade element). ${ }^{2}$

In the first experiment, we hired more than 380 workers for a three-hour data-entry job. Workers were paid a flat wage of 25 euros and were not aware that they were taking part in an experiment. The task consisted of manually entering surveys into a database. After the workers worked for roughly 100 minutes the treatment intervention took place. Depending on the treatment, the workers received no gift, a monetary gift (5 euros), a thank you card, or both the monetary gift and thank you card either with or without a

\footnotetext{
${ }^{1}$ Mauss (1925) was the first to systematically document the role of gifts for establishing reciprocal relationships.

${ }^{2}$ In other settings, a personalization (for example, the choice of a particularly suitable gift in kind) and a handmade element might have similar effects as personalization also conveys a personal investment of time and "thought." In the context of our anonymous, one-time interactions, personalization was not possible and a hand-made element seemed to be a more unequivocal sign of personal effort to create something "special." We do, however, think of a personal touch as essentially anything that renders a gift (including a thank you), more valuable to the recipients without affecting its market value.
} 
handmade element. The handmade element consisted of money folded like a bow tie and attached to the card. After the treatment intervention, workers worked for another hour.

The results show that both the monetary gift as well as the thank you card alone significantly increase performance as compared to workers who do not receive a gift. These effect sizes are not significantly different from one another and thus suggest that a thank you card and a 5 euro gift are equally effective in this setting. Interestingly, the combination of 5 euros and the thank you card without a handmade element does not increase performance, while the combination with a handmade element is very effective (the effect size is roughly double the effect size of the 5 euros and thank you card alone). The results suggest that the combination of money and gratitude only works when the giver puts personal care and effort into the gift.

To test the robustness of these results and to investigate the underlying mechanism, we designed a second field experiment, Experiment 2, using a different setting and a non-student subject pool. We sent out 1570 letters asking recipients to fill out and return a 10 minute survey. Depending on the treatment, the letters either contained a monetary gift, a combination of a monetary gift and a thank you card without a personal touch, or a combination of the two with a personal touch. This replicates our three main treatments from Experiment 1. ${ }^{3}$ The handmade element consisted of a hand-drawn sketch of a flower on the thank you card. The outcome variable of interest is whether or not a recipient completed and returned the survey. Again, we find that the impact of a combination of money and appreciation is highly sensitive to the presence of a personal touch: while the combination with a personal touch yielded a significantly larger response rate than money alone, the combination without a personal touch did not.

This set of treatments, like those in Experiment 1, cannot distinguish between an explanation in which the personal touch interacts with the combination of money and gratitude by making it effective, and an explanation in which the combination of money and gratitude itself has no motivational power (with or without personal touch), but in which the personal touch itself has a big positive effect on performance. To clarify this issue, we ran an additional treatment that added the personal touch only to the thank you card (without including the money). If the effectiveness of the combination of money and gratitude with the personal touch was driven solely by the personal touch, then this treatment should be at least as effective as the one that also included money. The results show that this is not the case, suggesting that the personal touch increases the effectiveness of the combination of money and gratitude. A final treatment, included as a robustness check, documents that the there were no additional benefits to be gained from changing the appearance of the financial component itself (as was done in Experiment 1 by folding the bill). A combination of money and gratitude with a personal touch that changes the appearance of the money (by placing the 1 euro coin into the middle of the flower as its blossom) is just as effective as the combination with personal touch and the "plain" 1 euro piece.

Taken together, these findings suggest that a personal touch (investment of time and effort) greatly

\footnotetext{
${ }^{3}$ To increase statistical power we limited the set of main treatments to the two combinations with and without personal touch and a reference treatment, money alone (1 euro, approx. \$1.1).
} 
enhances the effectiveness of a thank you that comes with a financial reward. These findings can be rationalized with research from sociology and psychology that argues that the type of gift and its presentation symbolize the character of the relationship between parties (Zelizer, 1994). While a purely monetary gift signals an economic-exchange relationship, a non-monetary gift such as the expression of gratitude conveys a social-exchange relationship where money is not acceptable as a gift (Heyman and Ariely, 2004; Pieters and Robben, 1999; Webley and Wilson, 1989). A conflict may arise if the gift sends mixed signals. This can explain why money and a thank you work well in isolation but not in the simple combination (at least not better than money or a thank you alone). Our results suggest that the investment of time and effort can counteract this mechanism and make the combination "acceptable."

The paper proceeds as follows: Section 2 presents a short overview of the literature. Sections 3 and 4 describe the experimental set-up and results of Experiments 1 and 2, respectively. Finally, section 5 discusses the results and concludes.

\section{Literature}

The academic literature to date has focused on a relatively narrow swath of the gift-giving domain: responses to financial gifts. In his groundbreaking article, Akerlof (1982) explains the persistence of above-market clearing wages and unemployment with the fact that workers reciprocate wage gifts with higher effort. A large number of empirical studies have since confirmed this mechanism (for instance, Fehr et al., 1993; Fehr and Gächter, 2000; Charness, 2004; Bellemare and Shearer, 2009). Very little is known about nonfinancial gifts. ${ }^{4}$ An important exception is Kube et al. (2012), who show that the effort elicited is much lower for a financial gift of 8 euros than for a nicely wrapped thermos bottle of equal value, ruling out alternative explanations such as differences in perceived value and transaction costs. This suggests that non-pecuniary gifts might actually be more effective than financial gifts in triggering reciprocity. ${ }^{5}$ They also show that money, nicely folded as origami, and gifts in kind can have similar effects. This study does not, however, explore the effectiveness of gifts with no material value. The simplest and most common way for employers to treat their workforce kindly is to show appreciation and to thank employees for their efforts. Such behaviors are, however, not well understood to date as there is little empirical evidence on the performance

\footnotetext{
${ }^{4}$ This scarcity of literature on unconditional nonfinancial gifts stands in contrast to the growing literature on nonfinancial rewards as incentives (which are conditional on performance). Examples include Kosfeld and Neckermann (2011), Gubler et al. (2013), or Ashraf et al. (2014) on awards as incentives, or Blanes i Vidal and Nossol (2011), Tran and Zeckhauser (2012), or Barankay (2011) on the power of relative rank information. Similarly, economic theory has started addressing the notion that employees do not only care about economic resources but also about non-monetary rewards that address socio-emotional needs such as respect and attention (Ellingsen and Johannesson, 2007; Dur, 2009).

${ }^{5}$ This is related to the theoretical literature that analyzes the prevalence of gifts in kind despite their obvious inferiority to cash (Waldfogel, 1993; Prendergast and Stole, 2001) and the literature that uses evolutionary arguments to make that point (e.g., Carmichael and MacLeod, 1997 and Camerer, 1988). Brock et al., 2014 also use gifts in kind (books inscribed with a thank you message) to elicit reciprocity.
} 
effects of gratitude and appreciation either as incentives or as unconditional gifts. ${ }^{6}$ This paper therefore includes both a financial gift and a gift free of material value in the form of gratitude and appreciation, as well as gifts that combine both elements.

A priori there is little reason to expect that gratitude and financial gifts interact in important ways when given in combination rather than in isolation. There is a strand of literature in organizational psychology, however, that argues that monetary incentives do not work well in combination with recognition. ${ }^{7}$ This is in line with Lourenço (2016) who finds in her field experiment with sales representatives that money and recognition (via awards) are substitutes. Both have a positive effect on performance when applied in isolation but the joint effect is not statistically distinguishable from the effect of money or recognition alone. Kvaløy et al. (2015), in contrast, find in their field experiment on worker effort that performance pay reduces performance unless it is accompanied by motivational talk, suggesting that performance pay and motivational talk are complements. ${ }^{8}$ To the best of our knowledge, such interaction effects have not yet been studied in the context of gift exchange.

We tie together these different pieces of the literature and address a number of open issues: we study whether or not gratitude and appreciation can trigger reciprocity; we compare the effect size of gratitude with that of a financial gift to assess its relative effect size; and we look at the effectiveness of gifts that combine money and appreciation. ${ }^{9}$ We go beyond these open questions in the literature by introducing another element into the study of gift exchange: a personal touch. That is, we vary the personal time and effort invested in the presentation of the gift. Although gifts commonly include a personal touch, we know little about if and how personal touches affect the effectiveness of a combined gift. $^{10}$

\footnotetext{
${ }^{6}$ Exceptions are McCullough et al. (2001) and Grant and Gino (2010) in social psychology who show that gratitude motivates individuals to engage in pro-social behavior.

${ }^{7}$ Stajkovic and Luthans (2003) report in their meta-analysis that combinations of financial incentives and performance-dependent recognition work less well than either money or recognition alone, unless performance feedback is also provided. They explain their findings by arguing that the interpersonal nature of recognition collides with the impersonal nature of money, and that feedback can help to clarify the situation. Predating these findings, Rousseau (1990) already suggested that recognition creates a "psychological contract" between the employer and the employee that is based on respect and trust (Robinson et al., 1994); adding performance bonuses to this "contract" may then be incongruent with the interpersonal climate.

${ }^{8}$ Kosfeld et al. (2016) find important interaction effects between recognition as an incentive and the presence or absence of meaning of work, but no interaction between a piece rate and the same variation in meaning of work. Hossain and $\mathrm{Li}$ (2015) also investigate how the provision of incentives interacts with the work context. They study whether crowding out of intrinsic motivation differs between a work situation that is described as a favor (social frame) and one that is described as a job (work frame).

${ }^{9}$ We use the terms gratitude and (worker) appreciation interchangeably throughout the paper. Both terms are meant to refer to generalized expressions of kindness that are free of material value and not tied to past or future recipient performance.

${ }^{10}$ It seems to us that ignoring the personal touch is akin to ignoring the size of a gift. Obviously, the personal touch does not affect the material value of the gift, but it affects its value in the eyes of the receiver (Robben and Verhallen, 1994).
} 


\section{Field Experiment 1: Gift Exchange and Employee Performance}

\subsection{Experimental Design}

For the experiment, German research institute - the Centre for European Economic Research (ZEW) - hired students for a one-time data entry job between November 2010 and February 2012. The institute conducted a large-scale survey where questionnaire responses could not be scanned by an automated process, but had to be entered into a database manually. For this job, we hired students from different universities in and around Mannheim via student job centers, flyers, and notes on bulletin boards. The announcement informed subjects that the research center needed short-term student helpers for a three-hour data entry job and that subjects would earn a fixed wage of 25 euros in total, which was a standard hourly wage rate for student research assistants at that time. Students could sign up for the job online and were subsequently contacted via phone to arrange a date and time. We minimized career concerns by informing participants that this was a one-time job. ${ }^{11}$ We invited subjects in groups of eight. Sessions took place in two locations and three time slots (morning, early afternoon, and late afternoon). All sessions were conducted by the same research assistant.

\section{Implementation}

Upon arrival, each participant was seated in front of a computer workstation. The work spaces were arranged in a U-shape with sufficient space between individuals to ensure that subjects did not feel like others could observe their work. Then all formalities (privacy policy, wage agreement) were taken care of and the 25 euros were paid in advance. This was done to ensure that participants understood that the payment was independent of performance. ${ }^{12}$ Subsequently, the participants received a short introduction to their employer (ZEW) and to the project to which the surveys belonged. The questionnaires were part of an evaluation project in the educational context and involved surveys from several hundreds of students on their school and career preferences. Additionally, a short briefing was given on how to file the answers from the questionnaires into the database. The data were filed via a web interface; hence, access to the internet was possible at any time. The interface was set up as an online version of the paper surveys that the participants had in front of them. Most survey questions were multiple choice, only a few questions required entering information from free text fields. A non-transparent box containing the questionnaires was placed in front of each participant, with an identical box next to it to deposit the completed ones. This prevented the participants from easily comparing their speed of work to that of those around them.

\footnotetext{
${ }^{11}$ Participating multiple times was not possible due to tax reasons, as participants would then have exceeded the threshold of earnings beyond which tax-based information needs to be collected. This would have caused substantial administrative expenses for fiscal reporting and was, hence, ruled out by the administration of the institute.

${ }^{12}$ This was perceived as natural in the setting as we took care of all administrative procedures (including the payment receipt) at that point.
} 
After the instructions were given, the research assistant left the room. She informed participants that she was working outside and was available for queries at any time, and that subjects could take breaks whenever necessary. These measures (individual breaks, payment in advance, internet access, absence of supervisor) were taken to give participants substantial leeway in the amount of time they spent on entering the questionnaires, approximating the leeway that employees typically have in their jobs. Furthermore, a collective break was avoided to minimize possible group effects and communication between participants. The task was exhausting and monotonous, and we do not assume that there was much intrinsic motivation involved in completing the task. In fact, participants commented on a feedback form that the job was boring.

The task allows us to measure both the quantity and the quality of data entry. We measure quantity via the number of entries of a participant. One entry corresponds to checking a multiple choice question box on the computer screen or typing one word in a free-text field of the data entry surface. Correctness of an individual entry is determined by whether or not the entry corresponds to what the majority of workers submitted for this particular question. This serves as a very reliable quality measure because each survey was entered on average 23.5 times (s.d.=8.6). Employers are typically interested in the number of correctly entered items, and not in the number of entered surveys per se. Therefore, we focus on correct entries as our main performance measure in the analysis, but also present statistics on total entries and error rates separately.

Eight subjects were assigned to each working session. However, since some subjects did not show up, the average number of participants per session was 6.7 (s.d.: 1.09). The timeline was as follows: The introduction lasted for about 20 minutes (s.d.: $4.8 \mathrm{~min}$.) on average. Then, participants worked on the task for roughly 100 minutes (s.d.: 6.4 min.). ${ }^{13}$ We refer to this first phase as working period 1. After working period 1, the research assistant entered the room, informed workers that the data transfer worked fine, and then initiated the treatment intervention. ${ }^{14}$ Depending on the treatment, she gave a monetary gift, gratitude, or both to all participants of a workgroup (see next section for details on the treatments). Subsequently, subjects worked for approximately one additional hour, which we refer to as working period 2. ${ }^{15}$ Working period 1 was longer than working period 2 to allow for variation in the length of the introductory period and to smooth out initial learning effects. After the second working period, feedback forms were handed out, which asked for improvement suggestions and comments on how we handled the short-term employment. These forms also allowed us to gather some information on individual characteristics like gender and field of study.

\footnotetext{
${ }^{13}$ The length of time dedicated to introductions and working periods 1 differed slightly between sessions due to delays in arrivals of participants and differences in the number of questions asked in the introduction.

${ }^{14}$ Specifically, she informed workers in all treatments that, with the help of the IT-department, she had checked whether the data transmission was functioning properly between each computer and the central data base as there had been some technical problems in the past. Technical problems occurred in the first sessions, rendering this statement necessary. To keep the instructions identical between sessions, we provided this information in all later sessions, too.

${ }^{15}$ The mean length of working period 2 was 55 min (s.d.: 4.1 min.). We account for differences in the length of working periods in the statistical analysis by using productivity per minute of working time as the dependent variable. Additionally, we control for the length of working period 1 in all regressions.
} 


\section{Treatments}

As described above, the treatment interventions took place after working period 1. The different scripts can be found in the Appendix. In all treatments, including the Control treatment, the research assistant informed workers that the data were transmitted correctly from all computers to the central server. Nothing else happened in the Control treatment, which allows us to measure the change in productivity over time without gifts but with disruption. ${ }^{16}$

In the treatment Thank You Card, the research assistant explained that the research team had decided, together with the president of the institute, to hand out a thank you card to all workers as a symbol of the institute's appreciation for the participants' support in entering the data. All cards were signed by the president of the institute. Subsequently, participants were called by their name and received their thank you card. Based on recent economic models which assume that workers receive a positive utility from socio-emotional gifts such as respect or manager attention (Ellingsen and Johannesson, 2007; Dur, 2009), we expect workers to respond positively to receiving the thank you card by increasing their work effort.

In the treatment Money, subjects were informed that the research team had decided to give them a wage gift of 5 euros. The 5 euro bill was handed out immediately after this announcement to all workers. According to established theories on reciprocity (see, for instance, Akerlof, 1982; Fehr and Gächter, 2000; Falk and Fischbacher, 2006), we expect workers to increase effort in response to the 5 euro wage gift.

The treatments Thank You Card and Giftmoney (TC Giftmoney) and Thank You Card and Money (TC Money) combined the 5 euro gift and the thank you card either with or without a personal touch. The personal touch was varied by either folding the 5 euro bill like a bow tie or butterfly, which is a common way of presenting cash gifts in Germany, in TC Giftmoney, or by attaching a plain and unfolded bill to the card in TC Money. This is the only difference between these two treatments. Obviously, folding the bill poses an additional cost in terms of time and effort on part of the giver and thus signals personal care.

Figure 1 illustrates all treatments with pictures.

\subsection{Results}

Table 1 reports descriptive statistics by treatment group. The sample contains 381 observations in total: 81 in Control, 82 in Thank You Card, 70 in Money, 72 in TC Giftmoney, and 76 in TC Money. ${ }^{17}$ Table 1

\footnotetext{
${ }^{16}$ In addition to the treatments reported in this paper, we conducted three additional treatments that investigated how the response to non-monetary rewards is affected by the scarcity of the non-monetary reward. The results are reported in Bradler et al. (2016) and Bradler et al. (2013).

${ }^{17}$ Four sessions (two of Control and two of Thank You Card) had to be dropped from the analysis due to server breakdowns during working time. Moreover, five participants had to be excluded from the analysis. Two of these were excluded due to physical restrictions (one person was visually impaired and could not read the screen, the other person was over 60 years old and did not know how to operate the computer mouse), while the three other participants were excluded because they applied for a job as a student assistant at ZEW, which might bias behavior due to career concerns. Our results are, however, robust to the inclusion of these participants.
} 
shows that the treatment groups are balanced with respect to gender and field of study and that sessions are spread out more or less evenly over the different times of day and locations. There are, however, some differences between treatments for organizational reasons. We therefore control for time of day as well as for day of week and location in all regressions. Dropping these control variables does not affect our results. As participants were randomized into treatments, we expected them to be balanced with respect to their baseline performance, that is, performance in the first working period. Nevertheless, we find that baseline performance in the treatments Money and TC Money differs from that in the control group. We will address this imbalance by controlling for baseline performance in the analyses below. The number of correct entries per minute of working time is our main performance measure, but we will also look at quantity and quality of data entry separately.

The raw data are presented in Figure 2. The figure displays the average change in performance from working period 1 to 2 for all treatments. As can be seen, performance in the Control group does not change markedly between the two working periods. In contrast, workers increase their performance in both the Thank You Card and the Money treatments. The effects are moderately large and similar for both treatments. Performance increases by 0.67 entries per minute (sd: $1.66 ; 4 \%$ increase) in the treatment Money and by 0.78 entries per minute (sd: $2.37 ; 5 \%$ increase) in the treatment Thank You Card. ${ }^{18}$ Performance does not, however, increase when the thank you and the money are combined without a personal touch (TC Money). The change in performance in this treatment is similar to that in the control group (0.02 entries; sd: 1.74). This stands in stark contrast to the increase observed when a personal touch is also included. In $T C$ Giftmoney workers submit on average 1.45 more entries per minute (sd:1.83) in working period 2 than in period 1 , which corresponds to a $10 \%$ increase in performance. This difference is surprising given that the material nature of the gifts is the same, namely a thank you card and a monetary gift of 5 euros. The only difference between TC Giftmoney and TC Money is the personal touch.

In order to analyze treatment effects beyond descriptive statistics, we estimate the following baseline equation:

$$
\begin{aligned}
y_{i, t=2}= & \alpha+\beta_{1} \text { Thank You Card }+\beta_{2} \text { Money }+\beta_{3} \text { TC Giftmoney }+\beta_{4} \text { TC Money } \\
& +\delta_{1} y_{i, t=1}+\delta_{2} y_{i, t=1}^{2}+\delta_{3} y_{i, t=1}^{3}+\sum_{j=2}^{8} \gamma_{j} r_{i, j}+\varepsilon_{i, s}
\end{aligned}
$$

where $y_{i, t}$ represents the performance of individual $i$ in working period $t$. We correct for initial performance differences between individuals $i$ by including their performance in the first period, as well as its squared and cubic terms, in all estimations. ${ }^{19}$ Additionally, all regressions control for rank-specific effects that are

\footnotetext{
${ }^{18}$ The effect size on the financial gift is in line with other field experimental evidence on reciprocity. In a very similar set-up (one-time data entry job, three hours, student workers), Kube et al. (2012) observe an increase in performance of 5\% following a wage gift of 7 euros. This increase is, however, insignificant in their study.

${ }^{19}$ Controlling for baseline performance in a linear, quadratic, and cubic form, renders our specification more flexible than a simple diff-in-diff estimation and allows us to control for mean reversion. We do find some evidence for mean reversion in our data.
} 
independent of the treatment, where $r_{i, j}$ is a dummy variable taking the value one if the individual $i$ was of rank $j$ in working period 1 , and taking the value zero otherwise. ${ }^{20}$ Standard errors are clustered by session, denoted by the subscript $s$.

The first column of Table 2 shows the results of estimating equation (1), and the second column adds additional control variables to the specification. ${ }^{21}$ The table shows that the inclusion of a full set of controls (gender, field of study, location, time of day, duration of working period 1, and group size) does not affect the results. When discussing the effect sizes, we will refer to the full model presented in column II. As can be seen, the results of the regression confirm what Figure 2 suggested. An expression of appreciation, treatment Thank You Card, has a positive and statistically significant effect on performance ( 0.82 correct entries per minute or 0.27 standard deviations more than the control group). The 5 euro wage gift, treatment Money, has a similar effect ( 0.66 correct entries per minute, or 0.21 standard deviations more than the control group). This effect is, however, only weakly statistically significant. These two coefficients are not statistically significantly different from one another (Wald test, $\mathrm{p}=0.90$ ). The regressions also confirm the stark difference between the two combination treatments with personal touch (TC Giftmoney) and without personal touch (TC Money). While the former improves performance by 1.54 entries per minute or by roughly 0.5 standard deviations in comparison to the control group, the latter shows no performance improvement. The difference in performance between TC Money and TC Giftmoney is statistically significant (Wald test, $\mathrm{p}<0.01$ ). Also, TC Giftmoney outperforms Money and Thank You Card (Wald tests, $\mathrm{p}=0.03$ for the comparison with Money, and $\mathrm{p}=0.08$ for the comparison with Thank You Card). ${ }^{22}$ This suggests that the reciprocal response to a combination of money and gratitude is highly sensitive to the presentation of the gift and only works well when personal care is invested in the combination.

Although correct entries are probably the most relevant output measure for the employer, it is informative to look at treatment effects on the quantity and the quality dimensions of output separately. These results are reported in columns III and IV of Table 2. In column III, the dependent variable is the total number of entries per minute as a measure of quantity. In column IV, the dependent variable is the error rate as a measure of quality. The error rate is calculated as total errors divided by total entries. Hence, a negative coefficient can be interpreted as a quality improvement. Baseline performance represents the outcome measure in question in working period 1. Estimates reveal that the effect of the Thank You Card is largely driven by an increase in the quantity of entries. Money, on the other hand, has a statistically insignificant effect on quantity, but

However, since the magnitude of mean reversion is low, a simple diff-in-diff model yields very similar results (see Table A1 in the Appendix).

${ }^{20}$ Although workers were not able to perfectly observe others' productivity, they may have been able to observe whether they belonged to the high or low performers within the session. Therefore, we control for effects which may be related to the performance rank of an individual in the session. Dropping these controls does not affect our results.

${ }^{21}$ In order to use all available information to precisely estimate the coefficients of our control variables, we include data from the three other, previously mentioned treatments in the regression that were run in exactly the same set-up, but address different research questions. Bradler et al. (2016) and Bradler et al. (2013) report the results from these treatments. Our results are robust to dropping these observations from the analysis.

${ }^{22}$ We find no evidence for gender differences in any treatments. 
increases quality by 0.6 percentage points. ${ }^{23}$ TC Giftmoney improves performance in both the quantity and the quality dimensions, while TC Money does not affect either of the two output dimensions. Our main results on correct entries are thus mirrored in the quantity dimension, with some of the effect sizes in Thank You Card and TC Giftmoney stemming from an improvement in quality. ${ }^{24}$

Summarizing the results of Experiment 1, we find that:

(1) Appreciation induces reciprocity, suggesting that it can serve as a cost-effective substitute for a financial gift when the goal is to increase subsequent worker performance.

(2) If the gift giver combines a thank you with a monetary gift and invests personal care in the presentation of the gift, then the reciprocal response is significantly larger than if the gift giver provided a monetary gift or gratitude alone.

(3) A combination of appreciation and money as a gift (without personal touch) does not work well. In our case, the response to this gift was even lower than the response to gratitude or money alone.

Our results are consistent with the notion that the impersonal nature of money interacts negatively with the personal nature of social rewards such as gratitude (Heyman and Ariely, 2004; Pieters and Robben, 1999). The idea is that each reward in isolation taps into its respective frame (social or financial exchange) and elicits the associated positive effort response, but that the combination sends mixed signals and is ineffective. By this logic, both a tip to a gardener for a job well done and a bouquet of flowers in response to a dinner invitation should be well received and reciprocated. A thank you card and cash in response to the dinner invitation, however, should not work well because it is generally unacceptable to reciprocate personal favors with money. Our results are consistent with the notion that personal care can mitigate any detrimental effect stemming from combining money with gratitude, most likely because it puts the combination as a whole into a social exchange frame. The idea is that nicely decorated cash can preserve the social nature of the combined gift by essentially conveying the message that this is a personal gift despite the fact that cash is given. ${ }^{25}$

Since there is little previous evidence on the impact of a personal touch and such interaction effects, we decided to run a second experiment that focuses only on combinations of money and gratitude with and without a personal touch. We intentionally opted for a different subject pool and setting in order to

\footnotetext{
${ }^{23}$ It is worth noting that the baseline level of quality was very high in all treatments, leaving very little room for quality improvements. In the control group, for instance, only $1.3 \%$ of all entries were incorrect.

${ }^{24}$ The short time horizon of the study as well as a lack of information on other outcome measures that are relevant in practice, including absences, retention rates, employee health and wellbeing, and employee selection, do not permit a final assessment of the profitability of the different treatment interventions. During the time frame of the experiment, however, none of the gifts paid off for the employer in terms of increased productivity relative to direct material costs.

${ }^{25}$ At German weddings it is, for example, commonplace to transform cash gifts into works of art. The transformation preserves the social nature of the gift (by putting a lot of effort and creativity into the presentation), while providing the newlyweds with financial means to buy whatever they need. In essence, the the personal touch changes the perception of money as a gift from thoughtless to thoughtful by conveying that one was willing to invest heavily in creating a special gift while giving the newlyweds what they probably need most: money for their honeymoon or for establishing their household. Our hunch is, however, that this only works in settings in which the use of cash is justifiable (e.g., Christmas gifts to teenagers, newlyweds, or employment settings).
} 
test the robustness of our previous results in a new context. Further, we added two additional treatments designed to rule out confounding factors. In particular, Experiment 1 cannot rule out the possibility that the positive effect of the combination with personal touch is driven entirely by the "handmade" element. That is, we cannot distinguish between the story above, in which the personal touch renders the combination of money and gratitude acceptable, and a story in which the combination remains "unacceptable" but the handmade element itself has a large positive effect on performance (resulting in a positive overall effect). If the latter were true, then a thank you card with the handmade element but without money, a treatment that Experiment 2 includes, should have at least as big an effect as the combination of all three (money, appreciation, and personal touch). Also, Experiment 1 added a personal touch via the money itself by folding the bill. Theoretically, it could also be the transformation of the money that drives the large positive effect in TC Giftmoney. Therefore, Experiment 2 includes a treatment in which the personal touch does not transform the money itself.

\section{Field Experiment 2: Gift Exchange and Survey Participation}

We ran Experiment 2 as part of a survey that the ZEW conducted among randomly selected citizens of Mannheim, a medium-sized city in Germany. As the completion of surveys requires time and effort from the respondents and as participation is typically voluntary, surveys present an ideal setting to study how gifts activate people's willingness to exert voluntary effort that benefits the principal (here the researcher conducting the study) with little or no benefit to themselves. ${ }^{26}$ Since the focus of Experiment 2 is on the personal touch and how it affects the effectiveness of gifts that combine money and appreciation, we chose a financial gift treatment as the baseline in this experiment. ${ }^{27}$ This allows us to compare the effectiveness of treatments with combinations of money, gratitude, and personal touch to the effectiveness of a single reward. We designed three treatments that replicate Money, TC Money, and TC Giftmoney from Experiment 1. This allows us to test the robustness of our initial findings in a different context. Two additional treatments, described below, address the different alternative explanations raised above.

\footnotetext{
${ }^{26}$ The analogue of this in organizations would be the multitude of "voluntary" activities and altruistic helping behaviors that employees cannot be forced to engage in but that are important for the organization as a whole. Typically, these behaviors can either be seen as purely altruistic or as contributions to public goods (where the private cost contributing exceeds the private benefit thereof). Experiment 1, by comparison, focused on a clearly delineated task that agents can be held responsible for. The setting in Experiment 1 therefore more closely corresponds to core components of an individual's job in the corporate context.

${ }^{27}$ We could also have chosen appreciation as the reference category, but opted for money as the baseline treatment to anchor our results in the existing literature on gift exchange that almost exclusively uses cash as gifts. That money itself has a positive level effect on survey response rates has already been documented in Falk (2007), Gneezy and Rey-Biel (2014), and Garner (2005). Therefore, we saw less need to include a control group without gifts in order to show this effect.
} 


\subsection{Experimental Design}

\section{Background \& Implementation}

The Centre for European Economic Research (ZEW) conducted a survey in summer 2014 among the population of Mannheim. The participants were contacted by mail and were asked to answer questions about their preferences for work conditions, including flexible working hours and 'working from home.'

Addressees received a cover letter, a survey of three pages, a prepaid envelope to use to return the survey, and, depending on the treatment, a small gift. The cover letter introduced the research institute and the PhD student who conducted the survey for her dissertation. ${ }^{28}$ Further, the letter briefly explained what the survey was about and that it was not necessary for the recipient to be currently employed in order to take part in the study. The researcher emphasized that the completion of the survey would not require more than 10 minutes and that participation in the study would help her to learn more about her research question. At the end of the letter, it was mentioned that participants would find a small gift in the envelope. Addressees could then either complete the survey online (with login and password) or fill in the paper version that was mailed to them, using the prepaid envelope to return the survey. The survey mainly consisted of multiple-choice questions and a small number of free-text fields. The questions elicited preferences about working conditions, hypothetical behavior under particular work conditions, and socio-economic characteristics such as gender, age, education, and current labor market status.

The survey was conducted with two different subject populations. The largest share of subjects were randomly chosen citizens of Mannheim. Treatments were equally distributed across the different districts of the city and across the student assistants who delivered the letters. Within each district, we randomized in a way that minimized spillover effects caused by neighbors talking with each other about the survey and their treatment. In low-density residential areas with single family homes, we varied treatments between closely located streets but not within a street. In high-density residential areas, we randomized treatments across different houses within a street. A total of 1226 households received letters in this way. A smaller share of surveys was additionally delivered by mail to individuals who formerly participated in studies by the ZEW and agreed to be contacted again for future studies. The research center wanted to include this group of subjects in the mailing as they expected a higher response rate due to this pre-selection. However, since there were only 344 valid addresses for subjects "with prior contact," we used this subject pool only for a subset of the treatments.

The survey was conducted in two waves. The first wave was sent out at the beginning of July 2014 to both subject populations. The second wave followed approximately 3 weeks later at the end of July 2014 and only targeted subjects without prior contact with the ZEW. In total, 1570 surveys were sent out. Table

\footnotetext{
${ }^{28}$ In order to keep the setting comparable to the first experiment, we wanted to ensure that there was a face associated with the interaction so that the recipients knew who put the present in their envelope and who was responsible for the personal touch. Therefore, the letter was written by a $\mathrm{PhD}$ student and also included a photo of her.
} 
3 gives an overview of the number of observations per treatment and population. As we observe subjects without prior contact in both waves and in all treatments, we are able to control for effects associated with the particular wave and subject population.

\section{Treatments}

In total, we ran five treatments in Experiment 2. Figure 3 displays the different treatment interventions.

Money is the baseline treatment. In this treatment, addressees received a 1 euro coin with the mailing. ${ }^{29}$ The coin was taped onto a small sheet of paper to prevent it from being lost or overlooked. To replicate the "simple" combination of money and gratitude without personal care, we designed a treatment Thank You Card and Money (TC \& Money). The thank you card was similar in spirit to the one in the first experiment, but simpler in design. It read "Thank you very much for your participation," and had a signature from the $\mathrm{PhD}$ student who conducted the survey. A 1 euro coin taped on a small sheet of paper (exactly like in Money above) was attached to the thank you card (see Figure 3). We added a personal touch to this combination by drawing a flower on the thank you card (treatment TC Flower \& Money). The hand-drawn sketch signals that the giver invested personal care, time, and effort similar to the folded bill in Experiment 1. These three treatments allow us to test the robustness of our findings from Experiment 1. In particular, they allow us to assess whether the effectiveness of the combination of money and gratitude is sensitive to the presence or absence of a personal touch in this setting as well, and how the effect sizes of the different combinations compare to that of money alone.

Since Experiment 1 had only one treatment with the personal touch, it cannot distinguish between the competing explanations for the effectiveness of TC Giftmoney. One explanation is that the personal touch changes the way in which the combination of money and gratitude affects behavior, for example, by turning the entire combination into a social gift that is acceptable and appreciated. A second explanation is that the combination remains ineffective but that the personal touch itself has a large positive effect on performance. If the latter were true, then we would expect a thank you card with a personal touch to have at least the same effect as the full combination of thank you card, money, and personal touch. The treatment Thank You Card with Flower (TC Flower), in which subjects received the thank you card with a hand-drawn flower sketch but without a euro coin, allows us to make that comparison.

In order to rule out that the transformation of the money itself played a big role for the results in Experiment 1, we added one additional treatment Thank You Card with Flower and Giftmoney (TC Flower \& Giftmoney). Here, addressees received the same thank you card with the hand-drawn flower, but, in contrast to TC Flower \& Money where the coin was taped onto a small sheet of paper and attached to the card, we

\footnotetext{
${ }^{29}$ It is not uncommon to pay small monetary amounts for survey participation. Especially in the field of market research, various internet platforms offer compensation to potential customers if they reveal their consumption behavior and preferences. http://www.mysurvey.com is one example of a provider that operates worldwide. http://www.internetpaidsurveys.com provides an overview of paid survey platforms in the US.
} 
now insert the coin into the flower so that it represents its blossom. ${ }^{30}$ TC Flower \& Giftmoney therefore replicates TC \& Giftmoney in Experiment 1, whereas TC Flower \& Money presents a combination of money and gratitude with a personal touch without the confounding factor of the transformation of the cash itself. Table 4 presents an overview of all treatments in both experiments.

\subsection{Results}

In the following, we analyze how the different treatments affect the survey response rate, our proxy for reciprocal behavior in Experiment 2.

Table 3 presents the response rates by treatment for subjects with and without prior contact with the research institute. As expected, the two populations show very different level effects. We therefore discuss the descriptive statistics by population. First, we turn to the response rate among subjects who had not participated in a ZEW study before. In the treatment Money, $18.3 \%$ of addressees responded. The response rate is similar in TC \& Money, the combination without personal touch $(17.1 \%)$. These response rates are not statistically distinguishable from each other (Fisher's exact test, $\mathrm{p}=0.72$ ). The combination with a personal touch (TC Flower \& Money), however, induces a substantially higher response rate: $27.2 \%$ of addressees responded to the survey in this treatment. This is statistically significantly larger than the response rate in the treatment with money alone (Money) (Fisher's exact test, $\mathrm{p}=0.04$ ).

Next, we test whether it is the personal touch itself that drives the large positive effect of TC Flower \& Money. The response rate of TC Flower, a thank you card with personal touch but without money, reveals that this is not the case. The response rate in this treatment is $14.2 \%$, which is significantly lower than the response rate in TC Flower \& Money (Fisher's exact test, $\mathrm{p}<0.01$ ) and not statistically distinguishable from the response rate in Money (Fisher exact test, $\mathrm{p}=0.22$ ). Similarly, we can rule out the hypothesis that the effectiveness of the personal touch depends on the presentation of the money. TC Flower \& Giftmoney, which combines gratitude and money with personal care and also changes the appearance of the cash by presenting it as the blossom of a flower, and TC Flower \& Money have very similar effects. The response rate in TC Flower \& Giftmoney is $25.2 \%$, which is not statistically significantly different from that in $T C$ Flower \& Money (Fisher's exact test, $\mathrm{p}=0.74$ ).

Due to the smaller sample size, we could only run three treatments (Money, TC Flower \& Giftmoney, and TC Flower \& Money) with the pool of individuals who had prior contact with the ZEW. The pattern of results for these treatments and this subject pool mirror the findings above for the population without prior contact: The two treatments that combine money and gratitude with a personal touch work similarly well (response rate $=64.4 \%$ in TC Flower \& Giftmoney, and 60.7\% in TC Flower \& Money) and substantially better than money alone (response rate $=49.1 \%$; Fisher's exact test, $\mathrm{p}=0.02$ and $\mathrm{p}=0.08$ on the respective

\footnotetext{
${ }^{30}$ Even though we do not directly change the appearance of the cash itself in this treatment, we call it Giftmoney to ease comparisons of treatments between the two experiments and to highlight that this treatment, just like the Giftmoney treatment in Experiment 1, also gives the money a gift-like appearance.
} 
comparisons).

Overall, these results are in line with our findings in Experiment 1. A combination of gratitude and a monetary gift with personal care and "thought" enhances reciprocity (in comparison to a monetary gift alone), whereas the same combination without personal touch does not. Similar to Experiment 1, we find that the reciprocal response to the combination without personal touch is even lower than the one to money alone. Again, this difference is, however, not statistically significant. The additional treatments clarify that the marked difference between the combinations with and without personal touch is driven by an interaction of the personal touch with the combination (rather than by a large main effect of the personal touch), and that the effectiveness of the combination does not depend on a change in the appearance of the cash component itself.

Probit regressions on whether or not a subject completed and returned the survey (by mail or online) confirm the results of the descriptive analysis. For the regressions, we pooled all observations and controlled for subject population and timing effects (first or second wave). ${ }^{31}$ The treatment Money is omitted and serves as the reference category. The results are presented in Table 5. Subjects in both TC Flower \& Giftmoney and TC Flower \& Money are roughly equally likely to respond to the survey (Wald test, $\mathrm{p}=0.99$ ), suggesting that the presentation of the money itself does not influence the effectiveness of combinations with a personal touch. Response rates in both treatments that combine money and appreciation with a personal touch are approximately 10 percentage points higher than the response rate in the treatment with money only. These differences are statistically significant. The response rate in TC Flower is not distinguishable from the response rate in money alone, but is statistically significantly lower than the response rates in both $T C$ Flower \& Giftmoney and TC Flower \& Money (Wald test, $=<0.01$ ). This rules out the alternative hypothesis that the large positive effect of a combination with personal touch is solely driven by the latter. We also checked whether our treatments interact with the gender of the participant and find no evidence for such effects. $^{32}$

\footnotetext{
${ }^{31}$ The results indicate that subjects with prior contact are approximately 33 percentage points more likely to respond to the survey than are subjects without prior contact. There are no significant differences in the response behavior between the first and the second wave.

${ }^{32}$ Just like Experiment 1, Experiment 2 does not allow for a final assessment of costs and benefits of the different treatment interventions. While the short time horizon and a lack of knowledge about benefits other than increased immediate productivity hindered a final assessment in Experiment 1, Experiment 2 lacks a (market) value for a completed and returned survey. One can, however, easily compare the costs per completed survey across the different treatments by considering the delivery and return costs per letter (2.05 euro) and the respective response rates. In the treatment with thank you card and flower (TC Flower) the response rate was $14 \%$, which translates into an average cost per completed survey of 14.64 euros. Money only (Money) had a response rate of $18 \%$ and, considering the additional cost of 1 euro per letter, yielded an average cost per completed survey of 16.94 euros. The combinations with personal touch induced response rates of 25\% (TC Flower Giftmoney) and 27\% (TC Flower Money), respectively. This implies average costs of 12.20 euros (TC Flower Giftmoney) and 11.30 euros (TC Flower Money) per completed survey, which renders those combinations as the preferable interventions not only for maximizing response rates, but also in terms of cost-effectiveness.
} 


\section{Discussion and Conclusion}

This paper presents the results from two field experiments that investigate how monetary gifts and worker appreciation as well as their combination affect the reciprocal behavior of agents. We show that gratitude alone induces reciprocity, and, in line with the literature on reciprocity, we also find that money has a moderate, positive effect on subsequent performance. Both experiments show that combinations of money and gratitude as gifts only work well when they are paired with a personal touch. This finding is robust across contexts (menial work such as data entry and voluntary contributions to a public good such as responding to a survey) and subject populations (students, non-students with and without prior exposure to the sponsoring organization). Experiment 2 demonstrates the mechanism: the personal touch changes the way in which the combination of money and gratitude affects behavior. It further shows that the effectiveness of the personal touch is independent of whether or not it changes the appearance of the cash component (plain versus folded/embedded in a flower). ${ }^{33}$

The explanation that can best rationalize our findings is that interactions between individuals and also between employers and employees occur in certain frames that are associated with distinct norms and expectations, and that rewards and gifts have an influence on what frame recipients perceive themselves to be in (Heyman and Ariely, 2004; Fiske, 1992; Zelizer, 1994). A financial gift might induce recipients to perceive themselves in an economic exchange or money market frame, characterized by payments, a positive reward-effort relationship, and cost benefit analyses. Gratitude and appreciation, on the other hand, might induce recipients to perceive the situation as a social exchange or social market frame, characterized by gifts, high effort levels irrespective of compensation, and altruism. In each frame, a positive effort response to an "appropriate" gift can be expected. Combinations of social and monetary rewards can be detrimental because they send mixed signals about the frame. Our findings are consistent with the notion that the personal touch helps to clarify the frame of interaction by strengthening the social/interpersonal component of the combination (Larsen and Watson, 2001), for example by decreasing the likelihood that the gift is perceived as instrumental rather than as kind (Beltramini, 1996, p.170). ${ }^{34}$

Just like any individual study, this study also has its limitations and opens avenues for future research. For example, it would be nice to observe the effectiveness of the gifts that we used over a longer time horizon and in a repeated setting. One obvious concern in this regard is that effect sizes might become smaller over time as individuals get used to the gifts in repeated interactions. This is an important point that this paper

\footnotetext{
${ }^{33}$ The ineffectiveness of gratitude and money as a joint gift might also explain why Kube et al. (2012) do not find a significant reciprocal response to their cash gift: They thanked subjects for their work while handing out the cash gift. That they do find positive reciprocity in response to a nicely wrapped thermos bottle is, then, consistent with our finding that combinations of money and gratitude work well when combined with a personal touch.

${ }^{34}$ In theory, the personal touch can operate through a range of different mechanisms. The most straightforward mechanism is that the personal touch directly shifts interactions into a social frame. Alternatively, the personal touch could signal something about the giver - that they are caring, or enterprising, artistic, etc. Whatever the mechanism, it is critical that it diffuses the tension between the financial and the social gift.
} 
cannot conclusively answer. There are, however, two arguments that suggest that our results should also hold in long-term workplace settings. First, it is likely that experienced workers respond even more strongly to gratitude and personal touches than our findings suggest. Experienced workers presumably care more about their social relationship with their supervisor, and are, hence, more sensitive to signs of appreciation and personal care than student workers in a one-time data entry job. Second, simple manipulations can help to prevent habituation or satiation effects (McSweeney, 2004; Rogers and Frey, 2016). Such manipulations are especially natural in the context of gift giving, where gift givers commonly understand that gifts should rarely, if ever, be repeated. One way to add a personal touch to gifts in ongoing gift-giving situations might be the selection of different, suitable gifts at different points in time. A second limitation refers to the generalizeability of the findings in Experiment 1 where we employed and observed mainly students as workers in a one-time data entry task. That Experiment 2 replicated the main findings among a subset of the general population, suggests, however, that the findings generalize at least beyond the specifics of the first experiment. A final limitation that our study shares with much of the literature is the narrow focus on immediate productivity as an outcome measure. Ideally, one would also like information on a broader set of outcome measures including absences, turnover rates, and worker health and wellbeing, in order to get a more complete picture of the overall effectiveness of the different gifts.

When putting our study into perspective, our results do not seem that surprising. Gift giving is a widespread phenomenon in organizations. According to Forbes, there is a $\$ 46$ billion market for employee recognition rewards, where most of the rewards are given as symbols of gratitude rather than as explicit incentives for outstanding performance. Practitioners are also well familiar with the role of a personal touch. A large number of practitioner handbooks emphasize the importance of gifts being personal or creative so that they aren't perceived as cheap instruments to elicit recipients' effort (for instance, Nelson, 2005). And many organizations do, in fact, make use of personalized rewards or rewards that are costly to the giver in terms of time and effort. Examples include hand-written notes, invitations to dinners or events with the gift giver, or personalized gifts, as well as symbolic rewards, such an honorary pins or flower bouquets. Our results are consistent with many of these rewards being designed to convey gratitude without falling prey to the mechanism that we uncovered. They do this by providing thoughtful gifts in kind rather than cash, or by providing symbols of gratitude deprived of any material value.

Perhaps more surprising is the absence of literature on nonpecuniary gifts, the personal touch, and interaction effects between different types of gifts. Our findings underline that gift exchange is a complex phenomenon and that more research is needed to fully understand the underlying mechanisms. 


\section{References}

Akerlof, G. A., 1982. Labor contracts as partial gift exchange. Quarterly Journal of Economics 97 (4), 543-69.

Ashraf, N., Bandiera, O., Lee, S. S., 2014. Awards unbundled: Evidence from a natural field experiment. Journal of Economic Behavior \& Organization 100, 44-63.

Barankay, I., 2011. Rank incentives: Evidence from a randomized workplace experiment. Mimeo, University of Pennsylvania.

Bellemare, C., Shearer, B., 2009. Gift giving and worker productivity: Evidence from a firm-level experiment. Games and Economic Behavior 67 (1), 233-244.

Beltramini, R. F., 1996. Gift giving: A research anthology. Bowling Green, OH: Bowling Green State University Popular Press., Ch. Business believes in gift giving.

Blanes i Vidal, J., Nossol, M., 2011. Tournaments without prizes: Evidence from personnel records. Management Science 57 (10), 1721-1736.

Bradler, C., Dur, R., Neckermann, S., Non, A., 2013. Reward expectancy and performance: A field experiment. Mimeo.

Bradler, C., Dur, R., Neckermann, S., Non, A., 2016. Employee recognition and performance: A field experiment. Management Science Forthcoming.

Brock, J. M., Lange, A., Kenneth, L. L., 2014. Giving and promising gifts: experimental evidence on reciprocity from the field. European Bank for Reconstruction and Development Working Paper No. 165.

Camerer, C., 1988. Gifts as economic signals and social symbols. The American Journal of Sociology 94 (Supplement), S180-S214.

Carmichael, H. L., MacLeod, W. B., 1997. Gift giving and the evolution of cooperation. International Economic Review 38 (3), 485-509.

Charness, G., 2004. Attribution and reciprocity in an experimental labor market. Journal of Labor Economics $22(3), 665-688$.

Dur, R., 2009. Gift exchange in the workplace: Money or attention? Journal of the European Economic Association 7 (2-3), 550-560.

Ellingsen, T., Johannesson, M., 2007. Paying respect. Journal of Economic Perspectives 21 (4), 135-150.

Falk, A., 2007. Gift exchange in the field. Econometrica 75 (5), 1501-1511. 
Falk, A., Fischbacher, U., 2006. A theory of reciprocity. Games and Economic Behavior 54 (2), 293-314.

Fehr, E., Gächter, S., 2000. Fairness and retaliation: The economics of reciprocity. Journal of Economic Perspectives 14 (3), 159-181.

Fehr, E., Kirchsteiger, G., Riedl, A., 1993. Does fairness prevent market clearing? An experimental investigation. Quarterly Journal of Economics 108 (2), 437-59.

Fiske, A. P., 1992. The four elementary forms of sociality: Framework for a unified theory of social relations. Psychological Review 99, 689-723.

Garner, R., 2005. Post-it note persuasion: A sticky influence. Journal of Consumer Psychology 15, 230-237.

Gneezy, U., Rey-Biel, P., 2014. On the relative efficiency of performance pay and noncontingent incentives. Journal of the European Economic Association 12 (1), 62-72.

Grant, A. M., Gino, F., 2010. A little thanks goes a long way: Explaining why gratitude expressions motivate prosocial behavior. Journal of Personality and Social Psychology 98 (6), 946-955.

Gubler, T., Larkin, I., Pierce, L., 2013. The dirty laundry of employee award programs: Evidence from the field. Harvard Business School NOM Unit Working Paper 13-069.

Heyman, J., Ariely, D., 2004. Effort for payment a tale of two markets. Psychological science 15 (11), 787-793.

Hossain, T., Li, K. K., 2015. Crowding out in the labor market: A prosocial setting is necessary. Management Science forthcoming.

Kosfeld, M., Neckermann, S., 2011. Getting more work for nothing? Symbolic awards and worker performance. American Economic Journal: Microeconomics 3 (3), 1-16.

Kosfeld, M., Neckermann, S., Yang, X., 2016. The effects of financial and recognition incentives across work contexts: the role of meaning. Economic Inquiry Forthcoming.

Kube, S., Marechal, M. A., Puppe, C., 2012. The currency of reciprocity: Gift exchange in the workplace. American Economic Review 102 (4), 1644-62.

Kvaløy, O., Nieken, P., Schöttner, A., 2015. Hidden benefits of reward: A field experiment on motivation and monetary incentives. European Economic Review 76, 188-199.

Larsen, D., Watson, J. J., 2001. A guide map to the terrain of gift value. Psychology \& Marketing 18 (8), 889-906.

Lourenço, S. M., 2016. Monetary incentives, feedback, and recognition - complements or substitutes? evidence from a field experiment in a retail services company. The Accounting Review 91 (1), 279-297. 
McCullough, M. E., Emmons, R. A., Kilpatrick, S. D., Larson, D. B., 2001. Is gratitude a moral affect? Psychological Bulletin 127, 249-266.

McSweeney, F. K., 2004. Dynamic changes in reinforcer effectiveness: Satiation and habituation have different implications for theory and practice. Behavior Analyst 27 (2), 171-188.

Nelson, B., 2005. 1001 ways to reward employees. Vol. 2. Workman Publishing Company, New York.

Pieters, R., Robben, H., 1999. Consumer evaluation of money as a gift: A two-utility model and an empirical test. Kyklos 52 (2), 173-200.

Prendergast, C., Stole, L., 2001. The non-monetary nature of gifts. European Economic Review 45 (10), $1793-1810$.

Robben, H. S. J., Verhallen, T. M. M., 1994. Behavioral costs as determinants of cost perception and preference formation for gifts to receive and gifts to give. Journal of Economic Psychology 15(2), 333-350.

Robinson, S. L., Kraatz, M. S., Rousseau, D. M., 1994. Changing obligations and the psychological contract: A longitudinal study. Academy of Management Journal 37 (1), 137-152.

Rogers, T., Frey, E., 2016. Changing behavior beyond the here and now. In Blackwell Handbook of Judgment and Decision Making Forthcoming.

Rousseau, D. M., 1990. New hire perceptions of their own and their employer's obligations: A study of psychological contracts. Journal of Organizational Behavior 11 (5), 389-400.

Stajkovic, A. D., Luthans, F., 2003. Behavioral management and task performance in organizations: Conceptual background, meta-analysis, and test of alternative models. Personnel Psychology 56 (1), 155-194.

Tran, A., Zeckhauser, R., 2012. Rank as an inherent incentive: Evidence from a field experiment. Journal of Public Economics 96 (9-10), 645-650.

Waldfogel, J., 1993. The deadweight loss of christmas. American Economic Review 83 (5), 1328-1336.

Webley, P., Wilson, R., 1989. Social relationships and the unacceptability of money as a gift. The Journal of Social Psychology 129 (1), 85-91.

Zelizer, V. A. R., 1994. The social meaning of money. Princeton University Press. 


\section{Tables and Figures}

Figure 1: Gifts in Experiment 1

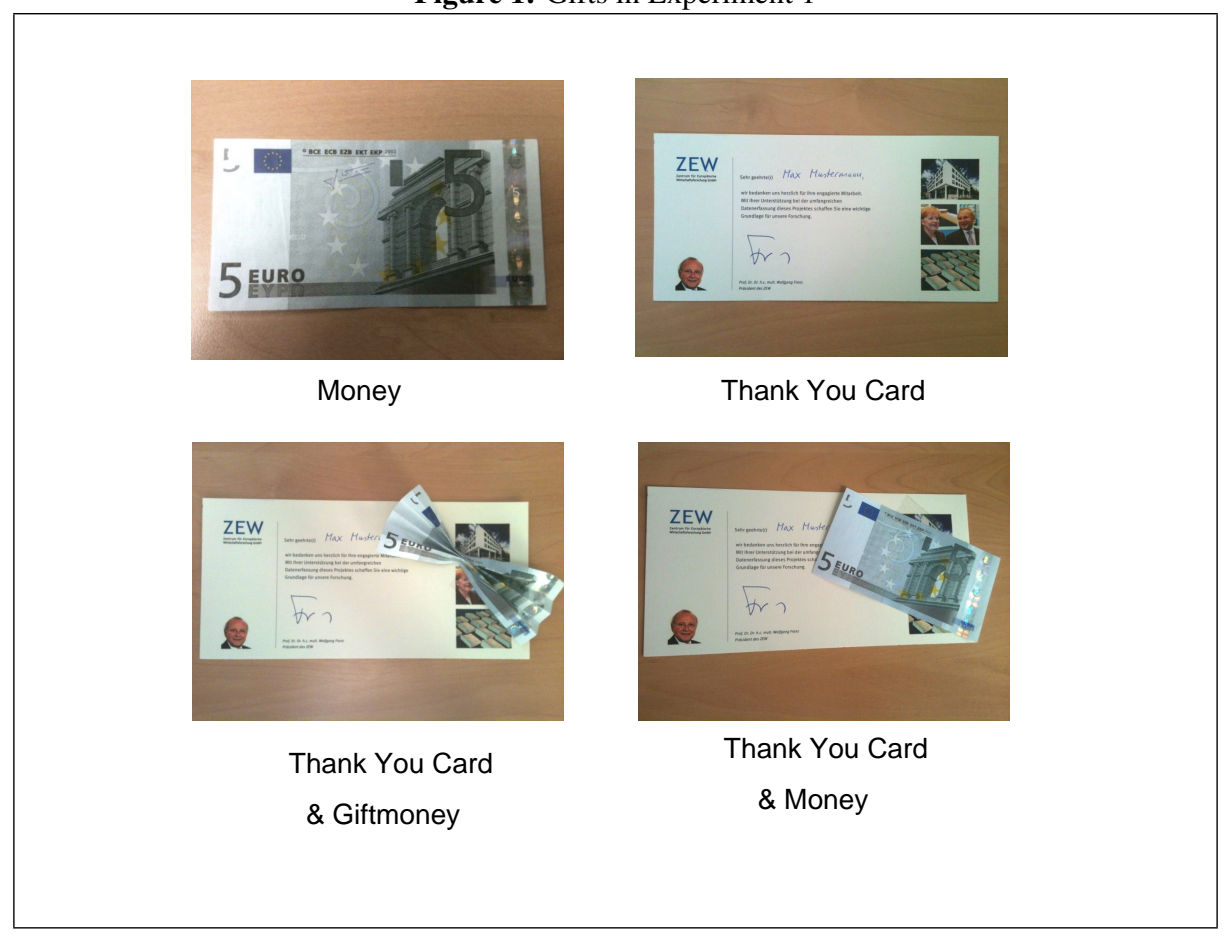

Note: The translation of the text on the card is: "Dear John Smith, we would like to thank you for your efforts Your work on this project's comprehensive data entry, will create an important foundation for our research." 
Table 1: Summary Statistics by Treatment Group

\begin{tabular}{|c|c|c|c|c|c|}
\hline & Control & Thank You Card & Money & TC Giftmoney & TC Money \\
\hline $\mathrm{N}$ & 81 & 82 & 70 & 72 & 76 \\
\hline Female & $\begin{array}{c}0.593 \\
(0.494)\end{array}$ & $\begin{array}{c}0.549 \\
(0.501)\end{array}$ & $\begin{array}{c}0.714 \\
(0.455)\end{array}$ & $\begin{array}{c}0.583 \\
(0.496)\end{array}$ & $\begin{array}{c}0.592 \\
(0.495)\end{array}$ \\
\hline Econ major & $\begin{array}{c}0.383 \\
(0.489)\end{array}$ & $\begin{array}{c}0.317 \\
(0.468)\end{array}$ & $\begin{array}{c}0.400 \\
(0.493)\end{array}$ & $\begin{array}{c}0.333 \\
(0.475)\end{array}$ & $\begin{array}{c}0.500 \\
(0.503)\end{array}$ \\
\hline Mannheim & $\begin{array}{c}0.556 \\
(0.500)\end{array}$ & $\begin{array}{c}0.427 \\
(0.498)\end{array}$ & $\begin{array}{l}0.700^{*} \\
(0.462)\end{array}$ & $\begin{array}{c}0.653 \\
(0.479)\end{array}$ & $\begin{array}{c}1.000 * * * \\
(0.000)\end{array}$ \\
\hline Morning & $\begin{array}{c}0.407 \\
(0.494)\end{array}$ & $\begin{array}{c}0.317 \\
(0.468)\end{array}$ & $\begin{array}{c}0.286 \\
(0.455)\end{array}$ & $\begin{array}{c}0.306 \\
(0.464)\end{array}$ & $\begin{array}{c}0.329 \\
(0.473)\end{array}$ \\
\hline Afternoon & $\begin{array}{c}0.235 \\
(0.426)\end{array}$ & $\begin{array}{c}0.402 * * \\
(0.493)\end{array}$ & $\begin{array}{c}0.400 * * \\
(0.493)\end{array}$ & $\begin{array}{c}0.486 * * * \\
(0.503)\end{array}$ & $\begin{array}{c}0.303 \\
(0.462)\end{array}$ \\
\hline Evening & $\begin{array}{c}0.358 \\
(0.482)\end{array}$ & $\begin{array}{c}0.280 \\
(0.452)\end{array}$ & $\begin{array}{c}0.314 \\
(0.468)\end{array}$ & $\begin{array}{c}0.208^{* *} \\
(0.409)\end{array}$ & $\begin{array}{c}0.368 \\
(0.486)\end{array}$ \\
\hline Group size & $\begin{array}{c}6.852 \\
(0.760)\end{array}$ & $\begin{array}{c}7.024 \\
(0.994)\end{array}$ & $\begin{array}{c}7.114^{* * *} \\
(0.843)\end{array}$ & $\begin{array}{c}6.194 * * * \\
(1.070)\end{array}$ & $\begin{array}{l}7.079^{*} \\
(0.935)\end{array}$ \\
\hline Duration of working period 1 & $\begin{array}{l}96.585 \\
(6.237)\end{array}$ & $\begin{array}{c}102.693 * * * \\
(7.516)\end{array}$ & $\begin{array}{c}100.815^{* * *} * \\
(6.482)\end{array}$ & $\begin{array}{l}96.097 \\
(4.272)\end{array}$ & $\begin{array}{l}97.745 \\
(3.958)\end{array}$ \\
\hline Mannheim University & $\begin{array}{c}0.259 \\
(0.441)\end{array}$ & $\begin{array}{c}0.305 \\
(0.463)\end{array}$ & $\begin{array}{c}0.486^{* * * *} \\
(0.503)\end{array}$ & $\begin{array}{c}0.417 * * \\
(0.496)\end{array}$ & $\begin{array}{c}0.658^{* * *} \\
(0.478)\end{array}$ \\
\hline Ludwigshafen University & $\begin{array}{c}0.210 \\
(0.410)\end{array}$ & $\begin{array}{c}0.134 \\
(0.343)\end{array}$ & $\begin{array}{l}0.100^{*} \\
(0.302)\end{array}$ & $\begin{array}{c}0.111 \\
(0.316)\end{array}$ & $\begin{array}{c}0.224 \\
(0.419)\end{array}$ \\
\hline Heidelberg University & $\begin{array}{c}0.506 \\
(0.503)\end{array}$ & $\begin{array}{c}0.549 \\
(0.501)\end{array}$ & $\begin{array}{c}0.386 \\
(0.490)\end{array}$ & $\begin{array}{c}0.417 \\
(0.496)\end{array}$ & $\begin{array}{c}0.118 * * * \\
(0.325)\end{array}$ \\
\hline Baseline performance & $\begin{array}{l}15.877 \\
(3.067)\end{array}$ & $\begin{array}{l}16.628 \\
(3.754)\end{array}$ & $\begin{array}{c}17.120 * * \\
(4.224)\end{array}$ & $\begin{array}{l}16.382 \\
(3.217)\end{array}$ & $\begin{array}{c}16.973 * * \\
(3.416)\end{array}$ \\
\hline
\end{tabular}

Note: The table reports means for each group. Standard deviations are displayed in parentheses. Significance levels indicate a difference of means (compared to the control group) and are denoted as follows: ${ }^{*} \mathrm{p}<0.1,{ }^{* *} \mathrm{p}<0.05, * * * \mathrm{p}<0.01$. Baseline performance is measured as correct entries per minute in working period 1. Note that observations in the control group as well as in the treatment Thank You Card are also used to make comparisons to different other treatments in Bradler et al. (2013a) and Bradler et al. (2013b). 
Figure 2: Improvement in Performance from Working Period 1 to 2 by Treatment

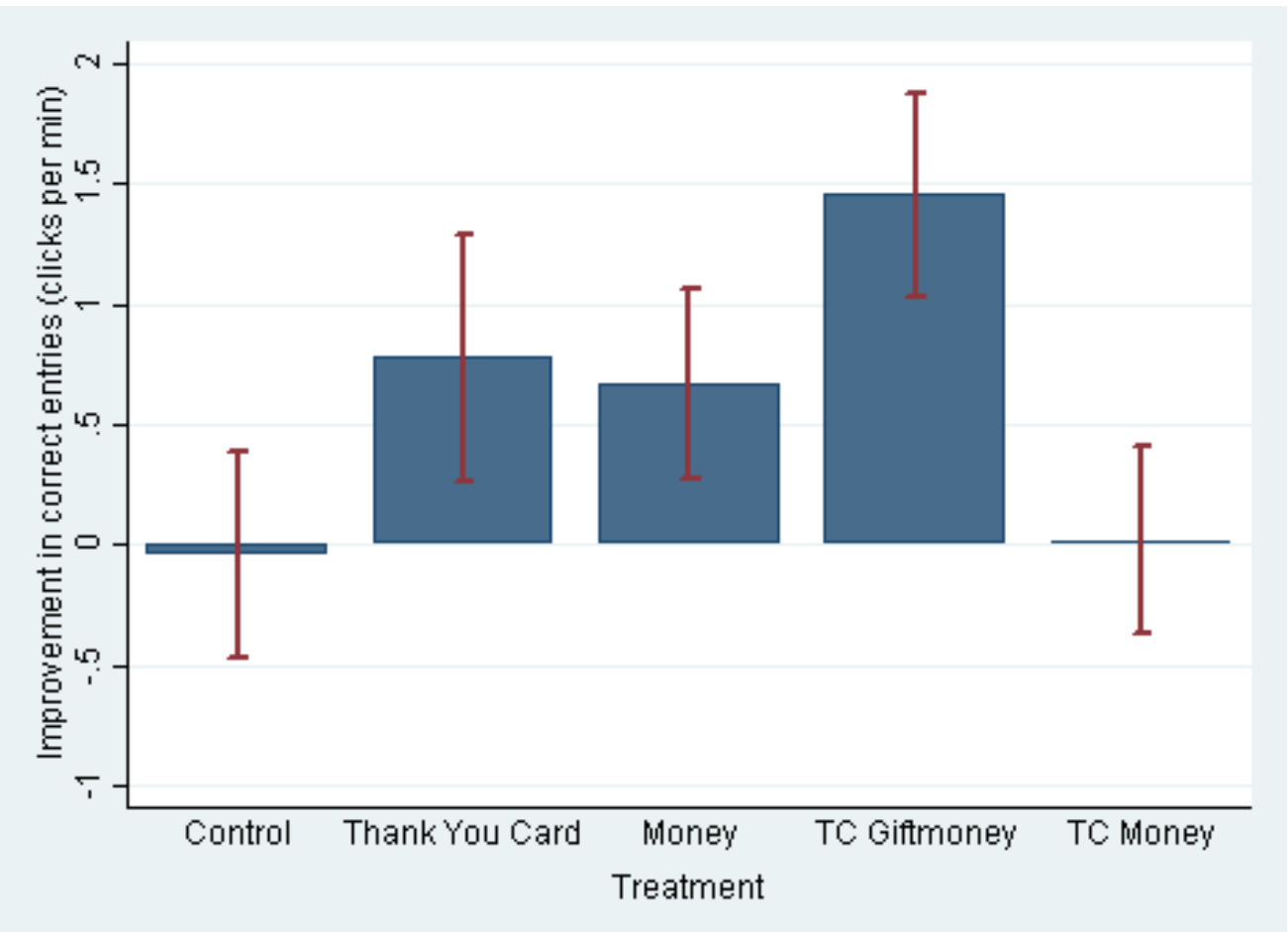

Note: The bars indicate the average change in correct entries from working period 1 to 2 by treatment. The whiskers depict the $95 \%$ confidence intervals. 
Table 2: Treatment Effects on Productivity in Working Period 2

\begin{tabular}{|c|c|c|c|c|}
\hline & \multicolumn{2}{|c|}{ Correct entries } & \multirow{2}{*}{$\begin{array}{c}\text { Total entries } \\
\text { III }\end{array}$} & \multirow{2}{*}{$\begin{array}{c}\text { Error rate } \\
\text { IV }\end{array}$} \\
\hline & I & II & & \\
\hline Thank You Card & $\begin{array}{l}0.839 * \\
(0.439)\end{array}$ & $\begin{array}{l}0.818 * \\
(0.433)\end{array}$ & $\begin{array}{l}0.759 * \\
(0.451)\end{array}$ & $\begin{array}{l}-0.401 \\
(0.311)\end{array}$ \\
\hline Money & $\begin{array}{l}0.727 * \\
(0.381)\end{array}$ & $\begin{array}{l}0.659 * \\
(0.356)\end{array}$ & $\begin{array}{c}0.564 \\
(0.374)\end{array}$ & $\begin{array}{c}-0.597 * \\
(0.339)\end{array}$ \\
\hline TC Giftmoney & $\begin{array}{c}1.543 * * * \\
(0.389)\end{array}$ & $\begin{array}{c}1.539 * * * \\
(0.369)\end{array}$ & $\begin{array}{c}1.479 * * * \\
(0.383)\end{array}$ & $\begin{array}{l}-0.464 * \\
(0.278)\end{array}$ \\
\hline TC Money & $\begin{array}{c}0.140 \\
(0.397)\end{array}$ & $\begin{array}{c}0.022 \\
(0.388)\end{array}$ & $\begin{array}{l}-0.041 \\
(0.408)\end{array}$ & $\begin{array}{l}-0.373 \\
(0.373)\end{array}$ \\
\hline $\begin{array}{l}\text { Controls } \\
\text { Baseline performance } \\
\text { Demographics } \\
\text { Other controls }\end{array}$ & Yes & $\begin{array}{l}\text { Yes } \\
\text { Yes } \\
\text { Yes }\end{array}$ & $\begin{array}{l}\text { Yes } \\
\text { Yes } \\
\text { Yes }\end{array}$ & $\begin{array}{l}\text { Yes } \\
\text { Yes } \\
\text { Yes }\end{array}$ \\
\hline $\begin{array}{l}\text { Observations } \\
\text { Sessions } \\
R^{2}\end{array}$ & $\begin{array}{c}627 \\
91 \\
0.776\end{array}$ & $\begin{array}{c}627 \\
91 \\
0.780\end{array}$ & $\begin{array}{c}627 \\
91 \\
0.779\end{array}$ & $\begin{array}{c}627 \\
91 \\
0.246\end{array}$ \\
\hline
\end{tabular}

Note: This table report OLS coefficient estimates (standard errors clustered by session are reported in parentheses). In columns I and II, the dependent variable is a worker's performance in the second working period measured by the number of correct database entries per minute. In column III, the dependent variable is a worker's total number of entries made in the second working period. The error rate is calculated by dividing total errors by total entries. The treatment dummy Thank You Card represents the treatment in which all subjects in a work group received a thank you card after the first working period. Money refers to sessions where all subjects in a work group received an unconditional bonus of 5 euros. TC Giftmoney and TC Money indicate the treatments in which all subjects received both a thank you card and a 5 euro bonus. In TC Giftmoney the 5 euro bill was nicely folded like a bow tie or butterfly and taped onto the thank you card. In TC Money the 5 euro bill was attached as is to the thank you card. Treatment Control is omitted and serves as the reference category. All columns include controls for baseline performance, its squared and cubic terms, as well as the performance rank of participants in working period 1. Baseline performance is measured as the number of correct entries in working period 1 in columns I and II, as the total number of entries in working period 1 in column III, and as the error rate in working period 1 in column IV. Further, columns II-IV include controls for demographics such as gender, university, and field of study as well as other controls such as location, time of day, duration of working period 1, and group size. Note that all regressions also include dummies for and observations from three other treatments, which are reported in Bradler et al. (2013a) and Bradler et al. (2013b). The data are included to obtain more accurate estimates of the coefficients for the control variables. Significance levels are denoted as follows: * $\mathrm{p}<0.1, * * \mathrm{p}<0.05, * * * \mathrm{p}<0.01$. 
Table 3: Response Rate by Treatment and Population

\begin{tabular}{|c|c|c|}
\hline & $\begin{array}{l}\text { Subjects with } \\
\text { prior contact }\end{array}$ & $\begin{array}{c}\text { Subjects without } \\
\text { prior contact }\end{array}$ \\
\hline Money & $\begin{array}{c}49.1 \% \\
(\mathrm{~N}=114)\end{array}$ & $\begin{array}{c}18.3 \% \\
(\mathrm{~N}=202)\end{array}$ \\
\hline TC Flower \& Giftmoney & $\begin{array}{c}64.4 \% \\
(\mathrm{~N}=118)\end{array}$ & $\begin{array}{c}25.2 \% \\
(\mathrm{~N}=202)\end{array}$ \\
\hline TC Flower \& Money & $\begin{array}{c}60.7 \% \\
(\mathrm{~N}=112)\end{array}$ & $\begin{array}{c}27.2 \% \\
(\mathrm{~N}=202)\end{array}$ \\
\hline TC Flower & - & $\begin{array}{c}14.2 \% \\
(\mathrm{~N}=310)\end{array}$ \\
\hline TC \& Money & - & $\begin{array}{c}17.1 \% \\
(\mathrm{~N}=310)\end{array}$ \\
\hline
\end{tabular}

Note: Randomization was conducted with all addresses in the database for subjects with prior contact with the ZEW. Since the database included addresses that were no longer valid, for example, because the subject had moved to a new, unknown address, the number of observations varies slightly across treatments. Due to the limited sample size of subjects with prior contacts, we only ran three treatments with this population. Randomization among subjects without prior contact with the ZEW was done between streets in low density residential areas and within streets in high density residential areas. 
Figure 3: Gifts in Experiment 2

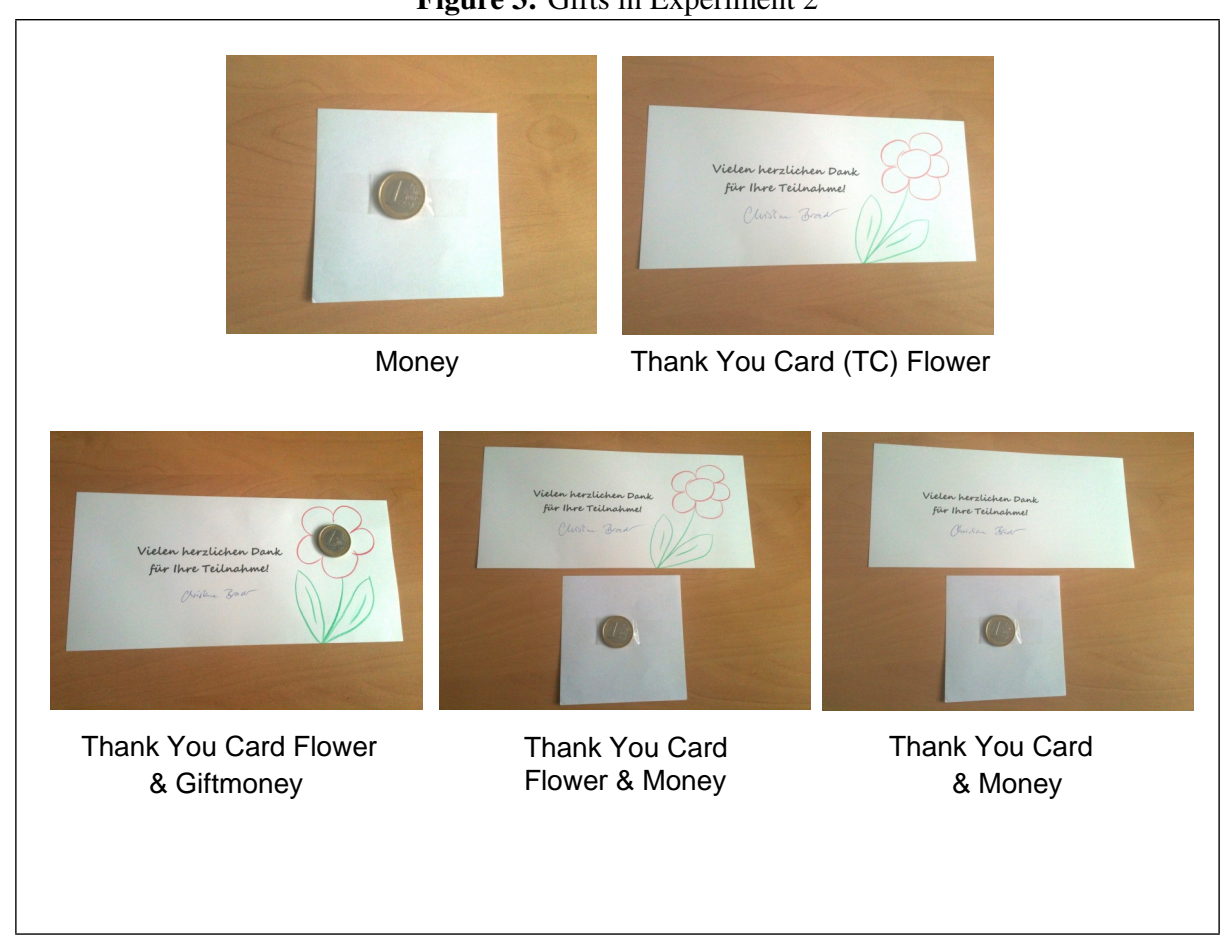

Note: The translation of the text on the card is: "Thank you very much for your participation!" 
Table 4: Overview of Treatments and Their Elements

\begin{tabular}{l|ccc|c}
\hline \hline & Money & Thank You & Personal Touch & Money Transform \\
\hline Experiment 1 & & & & \\
Control & & & & \\
Money & $\mathrm{X}$ & & & \\
Thank You Card (TC) & & $\mathrm{X}$ & & \\
TC \& Money & $\mathrm{X}$ & $\mathrm{X}$ & & $\mathrm{X}$ \\
TC \& Giftmoney & $\mathrm{X}$ & $\mathrm{X}$ & $\mathrm{X}$ & \\
\hline Experiment 2 & & & & \\
Money & $\mathrm{X}$ & & & \\
TC \& Money & $\mathrm{X}$ & $\mathrm{X}$ & & \\
TC Flower \& Money & $\mathrm{X}$ & $\mathrm{X}$ & $\mathrm{X}$ & \\
TC Flower & & $\mathrm{X}$ & $\mathrm{X}$ & $\mathrm{X}$ \\
TC Flower \& Giftmoney & $\mathrm{X}$ & $\mathrm{X}$ & $\mathrm{X}$ & \\
\hline \hline
\end{tabular}

Note: Money refers to treatments that have a financial component: a 5 euro bill in Experiment 1 and a one euro coin in Experiment 2. Thank You indicates treatments that include a thank you card. Thank you cards thanked participant for their efforts and were signed. Personal Touch indicates the presence of a handmade element in the combination of the thank you card and the money. This handmade element signals personal care and the investment of time and effort on the side of the gift giver. Money Transform refers to treatments in which the appearance of the cash component was changed. This was achieved by the folding of the money in Experiment 1 and the placement of the coin into the blossom of the hand drawn flower in Experiment 2. 
Table 5: Treatment Effects on the Response to the Survey

\begin{tabular}{lc}
\hline \hline & $(1)$ \\
& responded \\
\hline TC Flower \& Giftmoney & $0.103 * * *$ \\
$(0.038)$ \\
TC Flower \& Money & $0.103 * * *$ \\
& $(0.039)$ \\
TC Flower & -0.029 \\
& $(0.050)$ \\
TC \& Money & 0.010 \\
& $(0.052)$ \\
Prior Contact & $0.330 * * *$ \\
& $(0.035)$ \\
Second Wave & -0.023 \\
& $(0.043)$ \\
\hline Observations & 1570 \\
Pseudo $R^{2}$ & 0.111 \\
\hline
\end{tabular}

Note: This table reports marginal effects of a probit estimation. Robust standard errors are reported in parentheses. The treatment Money, where addressees received a small sheet of paper with a 1 euro coin taped onto it, is omitted and serves as the baseline category. The variable TC Flower \& Giftmoney indicates the treatment in which addressees received a thank you card with a hand-painted flower where the 1 euro coin was taped into the flower to represent its blossom. The variable TC Flower \& Money indicates the treatment in which addressees received a thank you card with a hand-painted flower and a separate small sheet of paper with a 1 euro coin taped onto it. TC Flower refers to the treatment in which addressees received a thank you card with a hand-painted flower but did not receive money. Finally, TC\& Money denotes the treatment in which addressees received a simple thank you card without a flower sketch but with a 1 euro taped onto a separate sheet of paper. The regression includes a dummy Prior Contact for subjects who had had prior contact with the ZEW and who had agreed to be contacted again for participation in scientific studies. The dummy Second Wave indicates whether the survey was sent out in the second wave of mailings. Significance levels are denoted as follows: * $\mathrm{p}<0.1, * * \mathrm{p}<0.05, * * * \mathrm{p}<0.01$. 


\section{Appendix}

\section{A Instructions}

\section{Experiment 1 Treatment Scripts (Original in German)}

\section{Control}

"May I bother you for a moment? With the help of our IT department, we did a brief check of the server. The data have been correctly transmitted from all computers so far. We were previously struggling with some software problems but now everything seems to work fine."

\section{Thank You Card (TC)}

"May I bother you for a moment? With the help of our IT department, we did a brief check of the server. The data have been correctly transmitted from all computers so far. We were previously struggling with some software problems but now everything seems to work fine. We would also like to take the opportunity to thank you in advance for your help. In preparation for this data-entry job, our president, Wolfgang Franz, and our research team have decided to give everyone this thank you card as a symbol of our appreciation and thankfulness for your support. [While handing out the cards:] Thank you very much for your effort!"

\section{Money}

"May I bother you for a moment? With the help of our IT department, we did a brief check of the server. The data have been correctly transmitted from all computers so far. We were previously struggling with some software problems but now everything seems to work fine. We would also like to take the opportunity to inform you that, given our budget available for this project, we decided to give you an extra payment of 5 euros."

\section{Thank You Card \& Giftmoney/ Thank You Card \& Money}

"May I bother you for a moment? With the help of our IT department, we did a brief check of the server. The data have been correctly transmitted from all computers so far. We were previously struggling with some software problems but now everything seems to work fine. We would also like to take the opportunity to thank you in advance for your help. In preparation for this data-entry job, our president, Wolfgang Franz, and our research team have decided to give everyone this thank you card as a symbol of our appreciation and thankfulness for your support. Given our budget available for this project, we also decided to pay you an extra payment of 5 euros which I have attached to the card. [While assigning the cards:] Thank you very much for your effort!" 


\section{B Appendix tables}

Table A1: Simple Diff-in-Diff Estimation of Treatment Effects on the Difference in Productivity between Working Periods 2 and 1

\begin{tabular}{lcc}
\hline \hline & I & II \\
\hline Thank You Card & $0.820^{*}$ & $0.796^{*}$ \\
& $(0.474)$ & $(0.461)$ \\
Money & $0.713^{*}$ & $0.706^{* *}$ \\
& $(0.371)$ & $(0.341)$ \\
TC Giftmoney & $1.496^{* * *}$ & $1.514^{* * *}$ \\
& $(0.375)$ & $(0.354)$ \\
TC Money & 0.064 & 0.027 \\
& $(0.381)$ & $(0.378)$ \\
Controls & & \\
Demographics & & Yes \\
Other controls & & Yes \\
\hline Observations & 627 & 627 \\
Sessions & 91 & 91 \\
$R^{2}$ & 0.082 & 0.091 \\
\hline
\end{tabular}

Note: This table report OLS coefficient estimates (standard errors clustered by session are reported in parentheses). The dependent variable is the difference in correct entries per minute between working period 2 and working period 1. The treatment dummy Thank You Card represents the treatment in which all subjects in a work group receive a thank you card after the first working period. Money refers to sessions where all subjects in a work group received an unconditional bonus of 5 euros. TC Giftmoney and TC Money indicate the treatments where all subjects received both a thank you card and a 5 euro bonus. In TC Giftmoney the 5 euro bill was nicely folded like a bow tie or butterfly and taped onto the thank you card. In TC Money the 5 euro bill was attached as is to the thank-you card. Treatment Control is omitted and serves as the reference category. Column II includes controls for demographics such as gender, university, and field of study as well as other controls such as location, time of day, duration of working period 1, and group size. Note that all regressions also include dummies for and observations from three other treatments, which are reported in Bradler et al. (2013a) and Bradler et al. (2013b). The data are included to obtain more accurate estimates of the coefficients for the control variables. Significance levels are denoted as follows: $* \mathrm{p}<0.1, * * \mathrm{p}<0.05, * * * \mathrm{p}<0.01$. 